\title{
THUCYDIDIS
}

\author{
DE

\section{BELLO PELOPONNESIACO}

LIBRI OCTO. 



\title{
THUCYDIDIS
}

\author{
DE \\ BELLO PELOPONNESIACO
}

L I B R I OCTO.

EX RECENSIONE

\section{IMMANUELIS BEKKERI.}

ACCEDUNT

SCHOLIA GRÆCA ET DUKERI WASSIIQUE ANNOTATIONES.

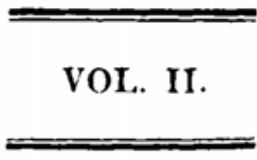

BEROLINI, APUD GEORGIUM REIMER.

1821. 
$\overline{\text { Excudebant S. et J. Collingwood, Oxonii. }}$ 